\title{
Can training for ethics in STEM benefit the workforce?
}

\begin{tabular}{|c|c|}
\hline $\begin{array}{l}\text { The ethics in science, } \\
\text { technology, engineering } \\
\text { and mathematics (E-STEM) } \\
\text { programme is a National Science } \\
\text { Foundation (NSF) funded } \\
\text { project at Gwynedd Mercy } \\
\text { University, Greater Philadelphia. } \\
\text { Dr Michelle Kulp McEliece and } \\
\text { her colleagues, Dr Christian } \\
\text { Hellings and Tara White Hines, } \\
\text { created the programme in } \\
\text { response to research which } \\
\text { suggests that a focus on ethics } \\
\text { in STEM can foster the ability } \\
\text { of students to become part of } \\
\text { the STEM workforce. E-STEM } \\
\text { uses evidence-based modules } \\
\text { that incorporate ethics, study } \\
\text { skills, peer mentoring and social } \\
\text { events to promote recruitment } \\
\text { in STEM subjects, boost } \\
\text { academic success, and improve } \\
\text { student retention rates. }\end{array}$ & $\begin{array}{l}\text { tudies suggest that to achieve } \\
\text { academic improvement for } \\
\text { academically promising students, } \\
\text { there is a requirement for study skills } \\
\text { development supplemented with social } \\
\text { support programmes. It has also been } \\
\text { shown that increased retention and overall } \\
\text { academic success can be achieved by } \\
\text { placing focus on emotional levelopment } \\
\text { alongside academic curricula. More } \\
\text { specifically, students taking science, } \\
\text { technology, engineering and mathematics } \\
\text { (STEM) majors can benefit from } \\
\text { combined academic support, social or } \\
\text { emotional support, and exposure to an } \\
\text { interdisciplinary curriculum. Additionally, } \\
\text { a focus on ethics in STEM has been shown } \\
\text { to foster analytical skills with a verbal } \\
\text { focus, and dilemma-based problem } \\
\text { solving has been shown to increase } \\
\text { students' understanding of fairness } \\
\text { and equality. } \\
\text { THE E-STEM PROGRAMME } \\
\text { In response to this evidence, the ethics } \\
\text { in science, technology, engineering } \\
\text { and mathematics (E-STEM) programme } \\
\text { has been developed to offer a modular }\end{array}$ \\
\hline
\end{tabular}

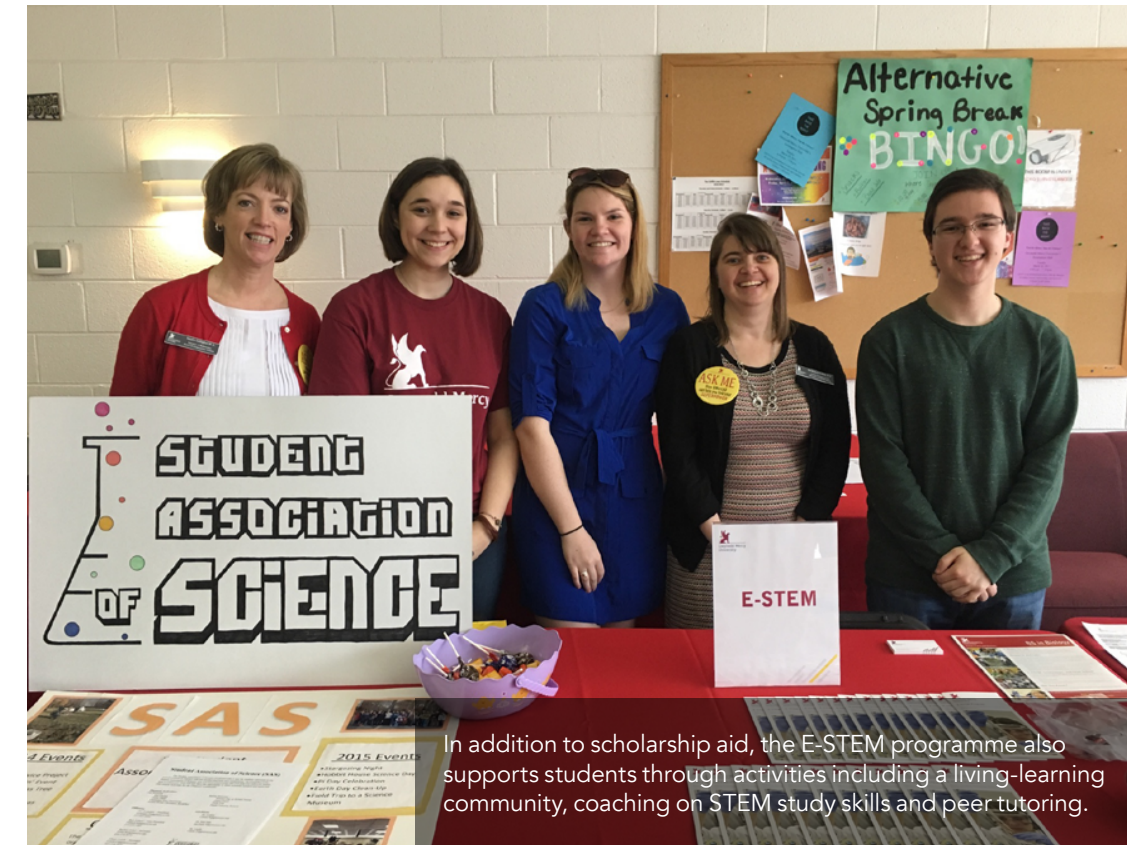

approach for capacity development. The ultimate goals of the project are to STEM fields, increase retention in STEM majors, and ensure more students go on to enter the STEM workforce. The programme, which was funded by the National Science Foundation (NSF), began in 2014 at Gwynedd Dr Michelle Kulp McElere leads the programme alongside colleagues Dr Christian Hellings and Tara White Hines.

A significant portion of the NSF grant supports scholarships for students pursuing a STEM major of biology, computer information science, or mathematics at Gwynedd Mercy University. The scholarships are designed to increase the number of students undertaking STEM degrees at the university by reducing the associated financial burden. E-STEM is also open to students that have not been awarded scholarships, and it has attracted number of such students.

\section{E-STEM ACTIVITIES}

In addition to scholarship aid, the E-STEM programme also supports students learning community, coaching on STEM study-skills, and peer tutoring. Ethics modules cover the foundations and the importance of ethics in STEM fields, using ethics scenarios, small group discussions, evaluation of ethical questions including how to dissect ethical questions, and research involving human subjects. Study skills modules include tutorials on note taking, test taking, and reading
scientific texts. This module also includes scientific texts. This module also includes examinations and evaluations of study guest speakers give participants an opportunity to learn from and increase professional connections with industry

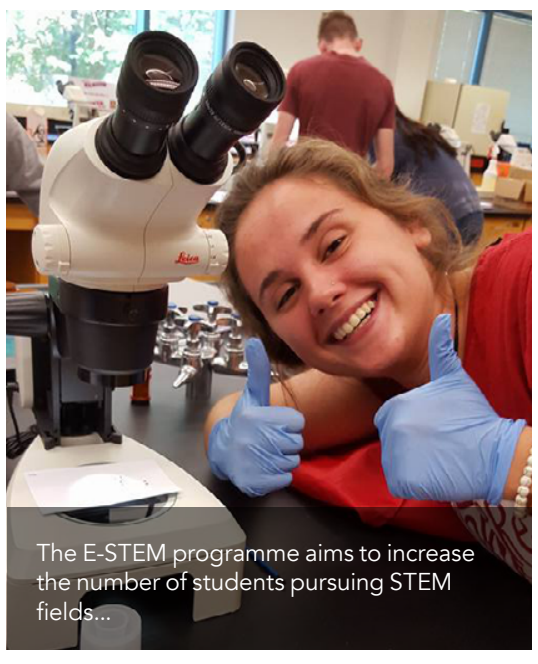

Peer mentoring based in collegiate development theory includes team building, study support, mentor-mentee pessions, and counselling training. The which are designed to promote team building and stress management.

Dr Kulp McEliece, who earned her Ph.D. in molecular biology from Lehigh University, is an Associate Professor of Biology at Gwynedd Mercy University She and her team devised the E-STEM programme with three major goals in mind.

STEM RECRUITMENT INITIATIVES E-STEM aims to increase enrolment in SEM subjects at their institution by $10 \%$ by providing scholarships to academically talented students with demonstrated financial needs. Each student must meet thenship, major, and GPA requirements to be accepted into the programme, with letters of recommendation and an essay. Dr Kup McEliece and her team are focusing on students interested in pursuing bachelor degrees in Gwynedd Mercy University's three STEM programmes: biology, computer information sciences, and mathematics.

A promotional campaign has been developed to accomplish E-STEM's recruitment goal, and a major objective of the programme is to implement at least three new recruitment activities to reach an increased number of academically talented students interested in STEM
professions. Activities which accomplished professions. Activities which accomplist of marketing materias promotion

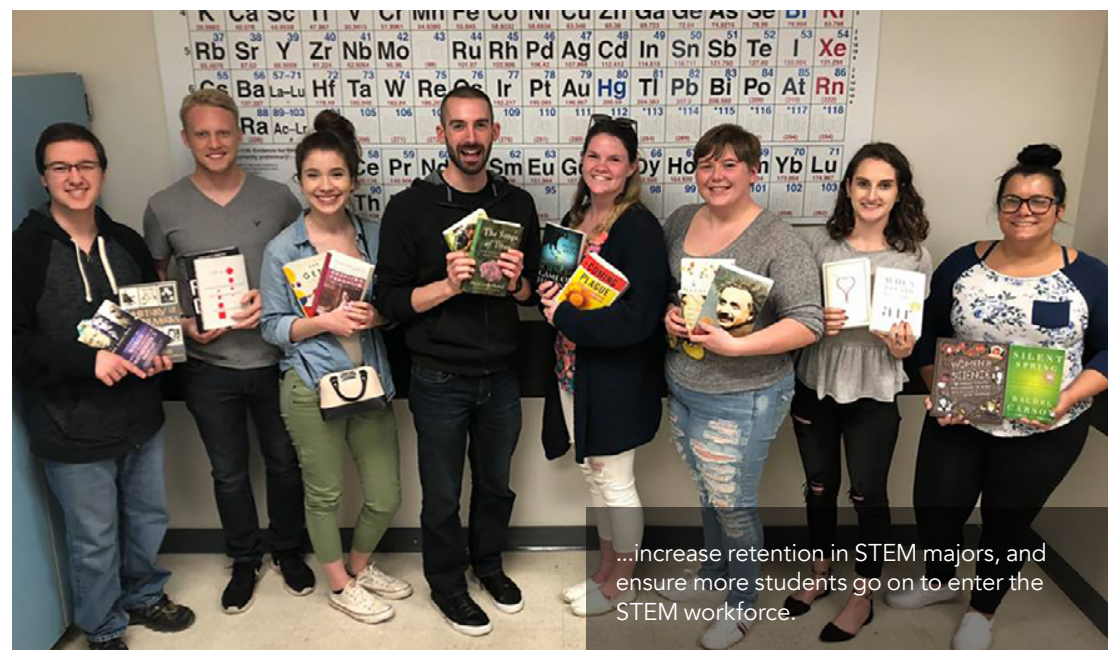

of E-STEM at University Open Houses, outreach by the university's admissions with accepted students. Jont and split cohort activities designed

INCREASING STEM RETENTION $\quad$ and in-person and online one-to-one The project a ro in by $90 \%$, while preparing conversations between participants STEM students for the workforce. E-STEM E-STEM students are given exposure to

E-STEM aims to ensure that at least $85 \%$ of students are employed or enrolled in a graduate programme within two years of graduation.

set a goal of increasing retention and graduation rates in the three targeted stem disciplines from the baseline six-year graduation rate of $50 \%$ and he baseline one-year retention rate of 78\%. E-STMM new and fou implement at least four activities, such as academic coaching peer mentoring and the creation of established living-learning community.

These objectives were achieved by creating a comprehensive programme

E-STEM Programming

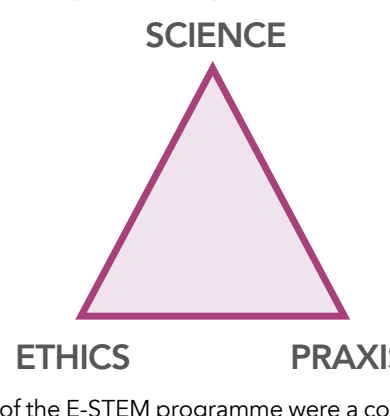

career options in STEM and they receive personalised advice from programme faculty members.

\section{BOOSTING STEM}

\section{TUUDENT SUCCESS}

E-STEM also aims to ensure that at least 85\% of E-STEM students are employed or enrolled in a graduate programme within two years of graduation. The project aim decision-making and ethical framework

- Ethics training modules

- Study skills

- Guest speakers

- Peer monitoring

- Social events

The pillars of the E-STEM program
and their subsequent interactions. 
Strategies to Achieve Programme Goals

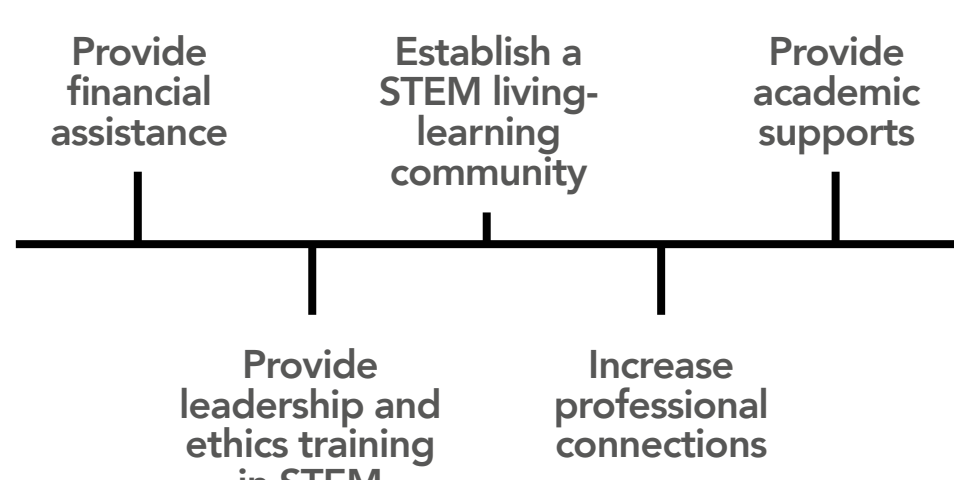

in STEM
ics A multif-faceted approach for supporting students in the E-STEM programme was used. This included
scholarships to decrease the known financial burden for students, as well as connection building and
leadership opportunities to foster a holistic network of benefits for the programme and beyond.

that employers seek. This training is especially important to internation importance of ethics This aspect of the programme is intended to inspire with graduating students not only strong knowledge and competencies in their subject but also a sound understanding of ethics in STEM.

This is achieved by developing and implementing ethics training modules an students understand their own ethical principles. The primary focus has shifted to dissect ethical questions, suppow decision-making and the deconstruction of real-life ethical scenarios such as authorship disputes and data sharing.

\section{OUTCOMES OF ETHICS IN STEM} Outcomes of the E-STEM programme are measured qualitatively via surveys, interviews, and focus groups, and required senior and mentor participation quantitatively via surveys, university

The E-STEM programme provides high academic advantages at low operational costs.

in leadership activities. Monthly ethics data, and national data. Data from sessions are held where discussions range the programme suggests that it has been importance to activities designed to help in its participants It also shows that the

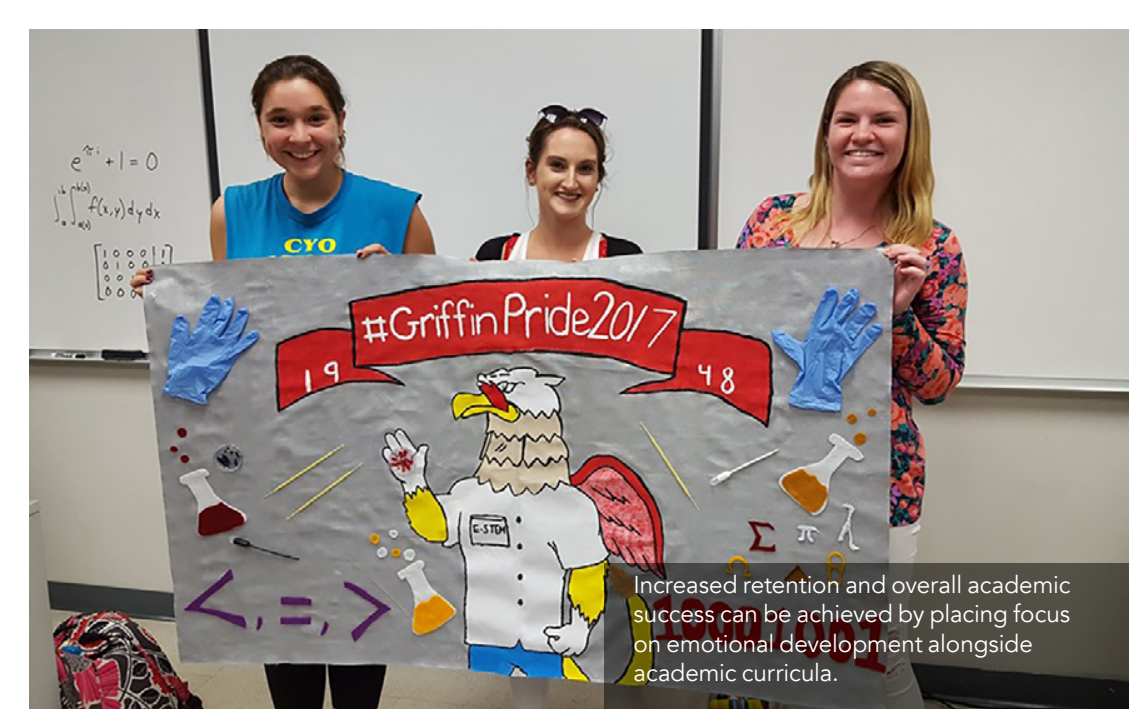

cohort model has benefitted participants and that every E-STEM alumnus is now

In 2018, the division saw a $21 \%$ uplift in applications from the previous academic year, and an average of $30.5 \%$ students indicated that the E-STEM scholarship was a factor in their attending or continuing at Gwynedd Mercy University.

E-STEM achieved a 78.6\% fall-to-fall retention rate for scholarship recipients, and participant satisfaction rates are consistently high across each completed year of the programme, with $100 \%$ micated perceived value of the mentormentee relationship.

Student success rates have been proven to be positive. Normative scores of

Gwynedd Mercy University are indicated to be statistically significantly higher than the national average. Self-reporting indicates "STEM employment readiness improvement" and "increased ethics capacity," which suggests that E-STEM is contributing to workforce needs. This is particularly evident in biology and information technology in the Greater Philadelphia region.

\section{PRELIMINARY CONCLUSIONS}

The E-STEM programme has been shown to provide high academic advantages at low operational costs and is a model that could be applied to numerous academic prallece the development of cohort identity has been crucial to the reported increase in academic achievement.

E-STEM graduates are shown to display higher moral and ethical development scores than their comparative peers, and it is evident that the programme promotes employment preparedness, academic retention, and self-reported value.

Looking more broadly, the programme has strengthened relationships with loca schools and employers. In addition,

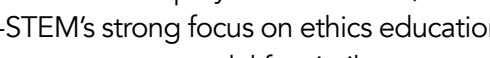
also serves as a model for similar

institutions in the region and beyond.

For more information visit www.gmercy edu/academics/e-stem-program

\section{Behind the Research}

Michelle Kulp McEliece, Ph.D.

E: mceliece.m@gmercyu.edu

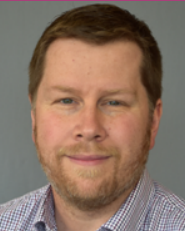

Christian Hellings, Ph.D.

: hellings.c@gmercyu.edu

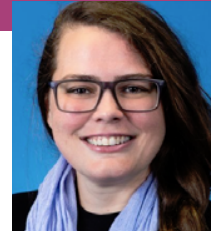

Tara White

Hines, MSPH

T: +1 215-646-7300 x21125 W: www.gmercyu.edu/academics/l-stem-program
s. 9 mercyuedu/estem-blog/? ga $=2.91748698 .1798908533 .1559655956-1751094079.1399563015$

\section{Research Objectives}

The Ethics in Science, Technology, Engineering, and Mathematics (E-STEM) programme at Gwynedd Mercy programm tad pumber of students pursuing and succeeding in STEM fields and, thus, participation in the STEM workforce.

\section{Detail}

Gwynedd Mercy University 1325 Sumneytown Pike, P.O. Box 901 , Gwynedd Valley, PA 19437

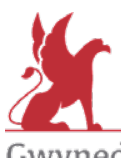
Gwynedd Mercy
University 列 Biology, Gwynedd Mercy University. Dr Kulp McEliece earned her BS in biology with a concentration in genetics and developmental biology from the Pennsylvania State University and her $P$ hD in molecular biology from Dr Ku Uc Eliece Bas a joining the GMercy faculty, Cancer Center

Christian Hellings, Ph.D., Associate Professor of Mathematics, Gwynedd Mercy University. Dr Hellings earned a Bachelor's degree with a dual major in mathematics and physics from La Salle University

Tara White Hines, MSPH, Healthcare Data Analyst, Bermuda Health Council. Tara Hines earned a BS in Biology with minors in microbiology, chemistry, and mathematics from Gwynedd Mercy University and her MS in Public Health, International Health with a Vaccine Sciences certificate from Johns Hopkins University, where she also worked as a mixed methods analyst at the Berman Institute of Bioethics.

Funding

National Science Foundation

\section{References}

Gwynedd Mercy University E-STEM Program; Ethics and STEM Capacity Building (2016). Michelle Kulp McEliece, AACU STEM Education conference.

\section{Personal Response}

Why is it important for more students with an aim to enter the STEM workforce? subjects II Michelle Kulp McEliece: Advancing and bettering society depends upon understanding the natural world
around us. It also requires us to understand how to harness and develop the technology that will allow us to do that. Students tend to avoid STEM disciplines because they view them as being too difficult, so it is important to show them how interesting STEM fields are and that they can be successful in them. Great feats of engineering, medical discoveries, improvements
to the environment - those are the results of STEM education. It is equally important for that education to include ethical methods in both research development and application.

II Tara White: The STEM discipline is one of the As careers become more technologically advanced, students with STEM backgrounds will be instrumental in every facet from engineering of a new system to understanding how to improve existing ones. A STEM degree can lead to positions in public policy, traditional It is an opportunity for people to find a passion that can change as the world does. 